\title{
Effects of growth hormone-releasing hormone and its agonistic and antagonistic analogs in cancer and non-cancerous cell lines
}

\author{
NEKTARIOS BARABUTIS ${ }^{1,2}$, AGNIESZKA SIEJKA ${ }^{1,3}$ and ANDREW V. SCHALLY ${ }^{1,2,3}$ \\ ${ }^{1}$ Veterans Affairs Medical Center and South Florida Veterans Affairs Foundation for Research and Education; \\ ${ }^{2}$ Department of Pathology and ${ }^{3}$ Divisions of Hematology/Oncology and Endocrinology, \\ Department of Medicine, University of Miami, Miller School of Medicine, Miami, FL 33125, USA
}

Received December 10, 2009; Accepted January 15, 2010

DOI: 10.3892/ijo_00000613

\begin{abstract}
The neuropeptide growth hormone-releasing hormone $(\mathrm{GHRH})$ is secreted by the hypothalamus and upon the binding to the receptors for GHRH on the pituitary gland regulates the release of growth hormone. Substantial evidence indicate that GHRH, in addition to its physiological role as a hypophysiotrophic hormone, acts as a growth factor in diverse tissues and various tumors. In this study we evaluated the expression of GHRH and its receptors in a variety of cancer and non-cancerous cell lines and studied the effect of GHRH antagonists and agonists on the proliferative cell nuclear antigen, cyclin D3, tumor suppressor protein p53 and carboxyl-terminal-binding protein (CtBP1). Our findings show that GHRH agonist JI-38 downregulates wt-p53 and upregulates the expression of PCNA. GHRH also upregulates $\mathrm{CtBP} 1$ protein expression and its antagonists downregulate it in LNCaP prostate cancer cells. Furthermore, GHRH and its agonist JI-38 upregulates the expression of the proliferative markers cyclin D3 and PCNA in A549 non-small cell lung carcinoma and GHRH antagonist MZ-5-156 downregulates it. Our results support previous findings on the mitogenic role of GHRH in cancers and underline the importance of GHRH antagonists as anticancer agents.
\end{abstract}

\section{Introduction}

Hypothalamic neuropeptide growth hormone-releasing hormone $(\mathrm{GHRH})$ is produced by the hypothalamus. Its full biologic activity is retained by the $\mathrm{NH}_{2}$-terminal 29 amino acid sequence (1). GHRH regulates the release of growth hormone $(\mathrm{GH})$ through binding to the GHRH receptors on somatotrophs. In turn GH stimulates the production of insulin-

Correspondence to: Dr Andrew V. Schally and Dr Nektarios Barabutis, Research Service (151), Veterans Affairs Medical Center, 1201 Northwest 16th Street, Miami, FL 33125, USA

E-mail: andrew.schally@va.gov

E-mail: nbarabutis@gmail.com

Key words: growth hormone-releasing hormone, growth hormonereleasing hormone receptor, growth factor like growth factor-I (IGF-1) (2). The receptor for GHRH (GHRH-R) is a G-protein-coupled receptor which is predominately expressed in the anterior pituitary gland. Upon binding of GHRH, GHRH-R increases the cellular second messenger cAMP in the somatotroph cells (3).

The endocrine function of GHRH and its receptor is not only limited to this hypophysiotrophic role. GHRH and its receptor are expressed in extrapituitary tissues and in various tumors, indicating a likely autocrine and paracrine role of GHRH in cancers (4). A splice variant of GHRH-R (SV1) was also recently identified and sequenced (2). Transfection of breast cancer cells with the pGHRH-R stimulates the baseline proliferation rate and responses to the mitogenic signal (5). The binding of GHRH to its receptor activates the mitogen-activated protein kinases pathway (MAPKs) ERK1/2 (6) as well as the JAK2/STAT3 pathway (7).

Recent studies indicate that the SV1 receptor possesses a ligand-independent activity $(5,8)$ and can also activate the ERK1/2 pathway in line with the pGHRH-R (6). Furthermore, the knocking down of the GHRH gene expression in lung, breast and prostate cancer cell lines dramatically reduces their proliferation rate (9), supporting the concept that GHRH is a growth factor in cancers (10). Interestingly, GHRH can influence the reduction/oxidation (redox) status of LNCaP prostate cancer cell line, increasing the production of the reactive oxygen species (ROS) (11).

This broad involvement of GHRH to a variety of malignancies and diseases related to the abnormal oxidative status of human cells, enhances the importance of the development of the GHRH antagonists. These agents, which have been developed by our group in the last decade, exert a strong antitumorigenetic activity in various experimental cancer models (12) and possess a strong antioxidant activity in a prostate cancer cell line (11). The likely role of GHRH antagonists as potential anticancer drugs is supported by the fact that GHRH agonists have strong mitogenic activity $(13,14)$. No side-effects by GHRH antagonists have been detected in any of the in vivo studies $(12,15)$.

In our present study we demonstrated the expression of GHRH receptor and its ligand in a series of tumor cells. We evaluated the influence of GHRH antagonist MZ-5-156, GHRH and GHRH agonist on the expression of important proliferative markers such as proliferative cell nuclear antigen (16), cyclin D3 (17) and the protein 'guardian of the genome' 
p53 (18). In addition we showed the influence of the GHRH and its antagonist on the expression of the co-repressor carboxyl-terminal-binding protein (CtBP1) (19-21) which plays a major role in tumor cell migration under hypoxic stress by sensing cellular redox changes (21).

\section{Materials and methods}

Peptides and chemicals. GHRH antagonists JMR-132 $\left[\mathrm{PhAc}^{0}, \mathrm{DArg}^{2} \text {, Phe (4-C) }\right)^{6}, \mathrm{Ala}^{8}, \mathrm{Har}^{9}, \mathrm{Tyr}(\mathrm{Me})^{10}, \mathrm{His}^{11}$, $\mathrm{Abu}^{15}, \mathrm{His}^{20}, \mathrm{Nle}^{27}, \mathrm{D}-\mathrm{Arg}^{28}, \mathrm{Har}^{29}$ ] GHRH (1-29) $\mathrm{NH}_{2}$, MZ5-156 [PhAc-Tyr ${ }^{1}, \mathrm{D}-\mathrm{Arg}^{2}$, Phe (4-CI) ${ }^{6}, \mathrm{Abu}^{15}, \mathrm{Nle}^{27}$ hGHRH (1-28)Agm], where Abu is $\alpha$-aminobutyric acid, Agm is agmatine, Har is homoarginine, Nle is norleucine, $\mathrm{PhAc}$ is phenylacetyl and $\operatorname{Tyr}(\mathrm{Me})$ is O-methyltyrosine, were synthesized in our laboratory by solid phase methods $(1,19)$. GHRH (1-29) $\mathrm{NH}_{2}$ and GHRH antagonists were dissolved in $0.1 \%$ DMSO and diluted with incubation media. GHRH agonist JI-38 was also synthesized in our laboratories as described previously (13).

Cell culture. All cancer cell lines were obtained from American Type Culture Collection (Manassas, VA) and cultured at $37^{\circ} \mathrm{C}$ in a humidified $95 \%$ air $/ 5 \% \quad \mathrm{CO}_{2}$ atmosphere. Breast cancer cell lines MCF7, MDA-MB-468, MDA-MB-435s, T47D, A549 and UMC11 non-small cell lung carcinomas (NSCLC), HeLa cervical cancer cell line, 3T3 mouse fibroblast cells, SKOV3 ovarian cancer cell line and WPMY-1 prostate stromal cell line were cultured in DMEM supplemented with antibiotics/antimycotics and $10 \%$ FBS. Prostate cancer cell line (LNCaP) was cultured in RPMI-1640 supplemented with antibiotics/antimycotics and $10 \%$ fetal bovine serum (FBS). Benign prostatic hyperplasia cell line BPH-1 was provided by Dr S.W. Hayward and cultured as previously described (22). All the culture reagents were purchased from Gibco (Carlsbad, CA).

Protein isolation and Western blot assay. The proteins were isolated from the cells using CelyticM lysis reagent (Sigma, St. Louis, MO) and the concentration of the isolated proteins was determined by Quickstart Bradford protein assay (BioRad, Hercules, CA) according to the manufacturer's instructions. Protein-matched samples (15 $\mu \mathrm{g} /$ lane $)$ were separated by electrophoresis using $12 \%$ sodium dodecyl sulfate SDS-PAGE Tris-HCl gels. Wet transfer was used to transfer the proteins onto nitrocellulose membranes (Bio$\mathrm{Rad})$. The membranes were incubated for $1 \mathrm{~h}$ at room temperature in 5\% non-fat dry milk in phosphate-buffered saline (PBS)-0.1\% (v/v) Tween-20. The blots were then incubated overnight at $4{ }^{\circ} \mathrm{C}$ with the appropriate primary antibody. The signal for the immunoreactive proteins was developed with peroxidase-conjugated secondary antibodies (Santa Cruz and Cell Signaling, Danvers, MA) and visualized by exposure to chemiluminescence substrate (Amersham Biotechnologies, Piscataway, NJ). The $B$-actin signal (1:1000, Santa Cruz) was used as control. The primary monoclonal antibodies raised against PCNA (no. 2586), cyclin D3 (no. 2936) and p53 (no. 9282) were purchased from Cell Signaling. The antibody raised against GHRH-R was purchased from Abcam (ab 28962-100). The antibodies
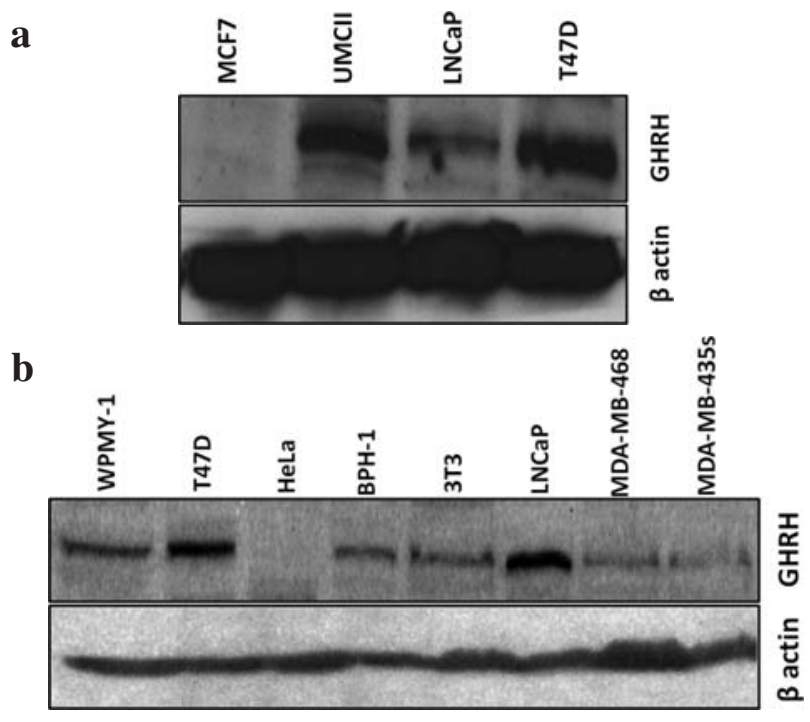

Figure 1. (a) Western blot analysis of expression of GHRH in UMC11 lung cancer cells. MCF7 breast cancer cell line was used as negative and LNCaP, T47D cells as positive controls. (b) Western blot analysis of expression of GHRH in WPMY-1 and 3T3 cell lines. MDA-MB-435s, MDA-MB-468, T47D breast and LNCaP prostate cancer cells were used as positive and HeLa cells as negative controls.

against B-actin (sc: 47778), GHRH (V-17) (sc: 10280) and Ct-BP1 (sc: 5961) were purchased from Santa Cruz Biotechnology (Santa Cruz, CA).

Quantitative analysis of the immunoblots. The protein band signals were quantified by Adobe Photoshop and normalized to the $B$-actin signal. The intensity of the bands was equal to their mean value multiplied by their pixel value (absolute intensity). Relative intensity (RI) of each band was calculated by dividing its absolute intensity by the absolute intensity of the control band ( $ß$-actin).

\section{Results}

Expression of GHRH in cancer cell lines and a benign prostate hyperplasia cell line. The expression of GHRH was examined by Western blots in UMC11 lung cancer cell line, with LNCaP prostate cancer cell line and T47D breast cancer cell lines as positive and MCF7 breast cancer cells as negative controls (9). UMC11 cells express this hormone. The results are shown in Fig. 1a. In addition, we examined the expression of GHRH by WPMY-1 prostate stromal cell line, BPH-1 benign prostate hyperplasia cell line and 3T3 mouse fibroblast cell line, using $\mathrm{LNCaP}$ prostate cancer cell line, MDA-MB-435s, MDA-MB-468 and T47D breast cancer cells as positive (9) and HeLa cervical cancer cells as negative controls (23). WPMY-1 and BPH-1 cells express GHRH. The results are shown in Fig. 1b.

Expression of GHRH receptor in cancer cell lines and a benign prostate hyperplasia $(B P H)$ cell line. The expression of growth hormone-releasing hormone receptor (GHRH-R) was examined by Western blot in A549 human lung carcinoma, using $3 \mathrm{~T} 3$ mouse fibroblast line and HeLa cervical cancer cell line as negative control. NSCLC A549 
a

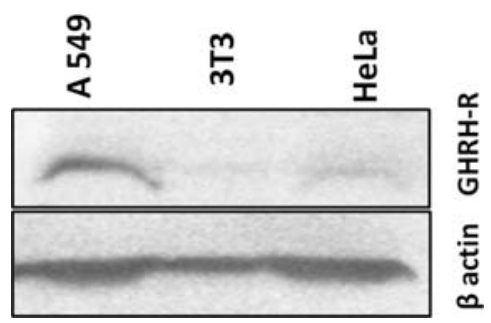

b

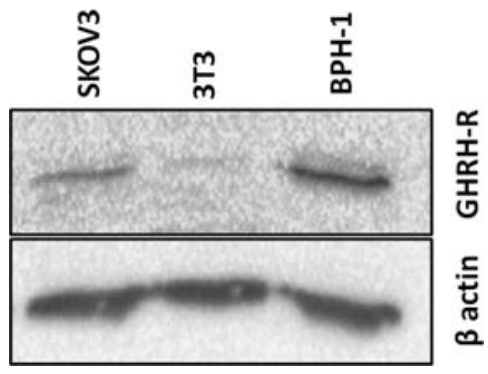

Figure 2. (a) Western blot analysis of expression of GHRH-R in A549 NSCLC lung cancer cell line. 3T3 mouse fibroblast line and HeLa cervical cancer cells were used as negative controls. (b) Western blot analysis of expression of GHRH-R in SKOV3 ovarian cancer cells. BPH-1 cells were used as positive and $3 \mathrm{~T} 3$ cells as negative controls.

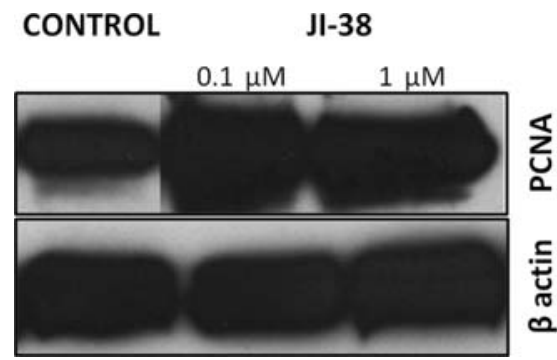

Figure 3. Western blot analysis of the effect of 0.1 and $1 \mu \mathrm{M} \mathrm{GHRH}$ agonist JI-38 on the expression of the PCNA in LNCaP cancer cells; $n=2$.

cells expressed GHRH-R and the results are shown in Fig. 2a. SKOV3 ovarian cancer cell line was also positive for the expression of this receptor. $\mathrm{BPH}-1$ cell line was used as positive and $3 \mathrm{~T} 3$ cells as negative control (8). The results are shown in Fig. 2b.

Expression of proliferative cell nuclear antigen after treatment of LNCaP prostate cancer cells with GHRH agonist. The expression of PCNA in LNCaP cells was increased after treatment of these cells with GHRH agonist JI-38 at the concentrations of 0.1 and $1 \mu \mathrm{M}$ with the relative intensity being 1.459 and 1.305 , respectively. The relative intensity of the control cells was 0.544 . The results are shown in Fig. 3.

Expression of proliferative cell nuclear antigen and cyclin D3 in NSCLC A547 cells after treatment with GHRH or GHRH antagonist. A549 cancer cells cultured in vitro were exposed to two concentrations of GHRH, GHRH agonist JI-38 and GHRH antagonist MZ-5-156. GHRH antagonist at 0.1 and $1 \mu \mathrm{M}$ decreased the expression of PCNA (RI: 0.669, 0.633 ) compared to the control cells (RI: 0.857). The results are shown in Fig. 4Aa. GHRH at concentrations of 0.1 and
Aa

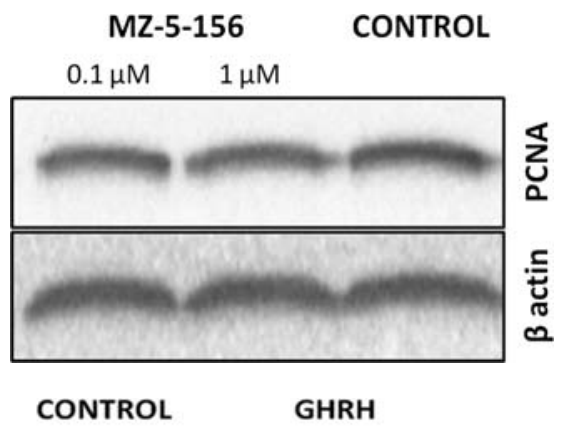

Ab
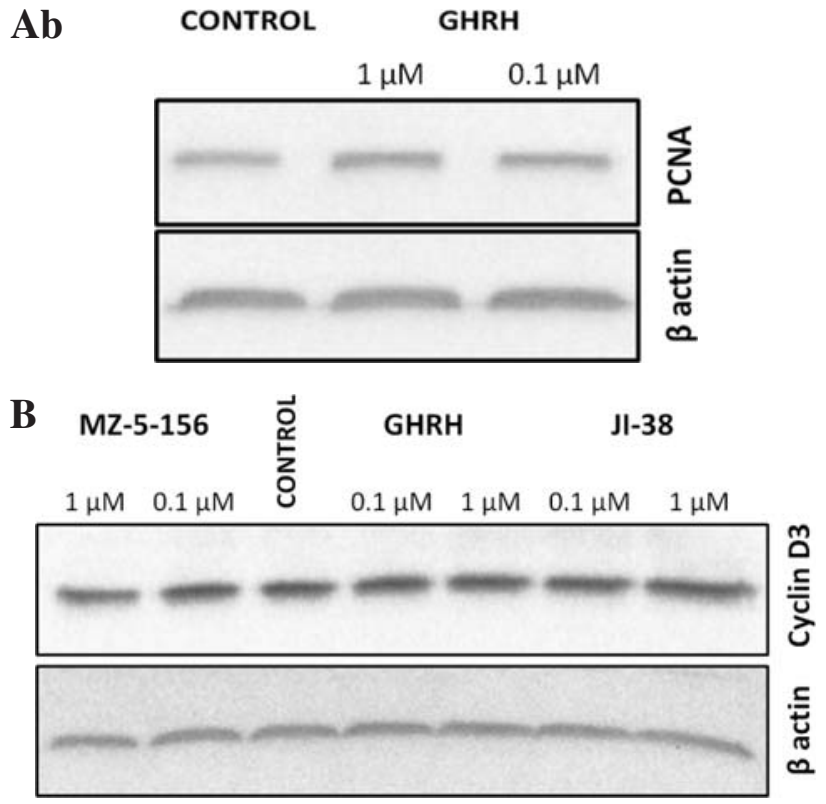

Figure 4. (Aa) Effect of 0.1 and $1 \mu \mathrm{M}$ GHRH antagonist MZ-5-156 on the expression of PCNA in A549 cancer cells; $\mathrm{n}=2$. (Ab) Effect of 0.1 and $1 \mu \mathrm{M}$ GHRH on the expression of PCNA in A549 cancer cells; $n=2$. (B) Effects of 0.1 and $1 \mu \mathrm{M}$ GHRH (1-29) $\mathrm{NH}_{2}$, JI-38 and MZ-5-156 on the expression of cyclin D3 in A549 cancer cells; $n=2$.

$1 \mu \mathrm{M}$, increased the expression of this marker. The relative intensity of PCNA after treatment with 0.1 and $1 \mu \mathrm{M} \mathrm{GHRH}$ was increased to 0.493 and 0.6 , respectively. The RI of the control cells was 0.449 . The results are shown in Fig. $4 \mathrm{Ab}$.

The expression of the cyclin D3 was also measured in the A549 NSCLC cells after exposure to GHRH, GHRH agonist JI-38 or GHRH antagonist MZ-5-156 at concentrations 0.1 and $1 \mu \mathrm{M}$. The expression of this marker was increased after exposure to GHRH (1-29) $\mathrm{NH}_{2}$ (RI: 1.02, 1.11) or JI-38 (RI: $1.12,1.28)$ and reduced after incubation of these cells with MZ-5-156 (RI: 0.98, 0.749) compared to the control cells (RI: 0.99). The results are shown in Fig. 4B.

Effect of GHRH (1-29)NH $\mathrm{NH}_{2}$ and GHRH agonist JI-38 on the expression on wild-type p53 tumor suppressor protein in LNCaP prostate cancer cells in vitro. LNCaP prostate cancer cells cultured in vitro were exposed to JI-38 and the expression level of wild-type p53 was measured by Western blot. P53 protein expression was lower in cells exposed to 0.1 and $1 \mu \mathrm{M} \mathrm{JI}-38$ (RI: $0.453,0.259$ ) compared to the control cells (RI: 0.59). The results are shown in Fig. 5.

Effect of GHRH (1-29) $\mathrm{NH}_{2}$ and GHRH antagonist JMR-132 on the expression of the carboxyl-terminal-binding protein 


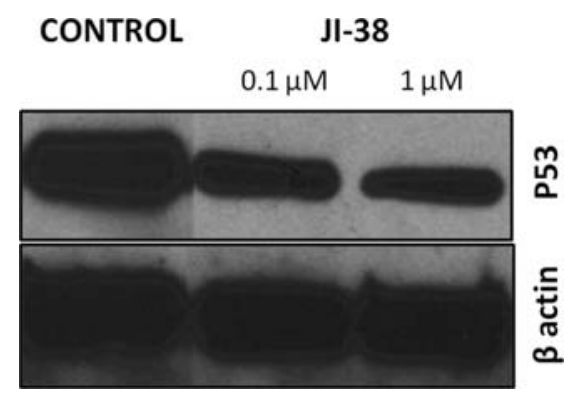

Figure 5. Western blot analysis of expression of wild-type p53 tumor suppressor protein in $\mathrm{LNCaP}$ cancer cells after $72 \mathrm{~h}$ exposure to 0.1 and $1 \mu \mathrm{M}$ JI-38.
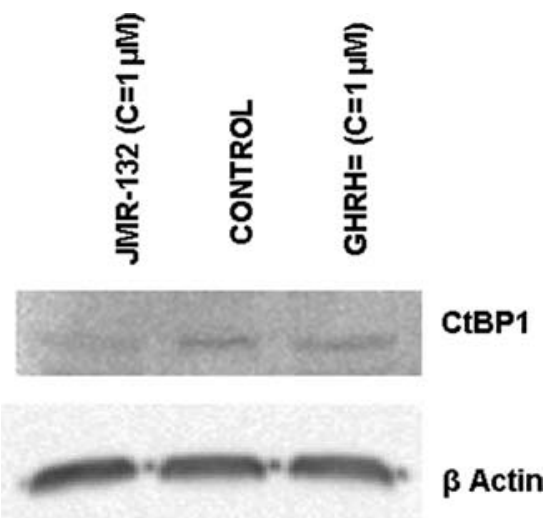

Figure 6. Western blot analysis of expression of CTBP1 in LNCaP cancer cells after $72 \mathrm{~h}$ exposure to 0.1 and $1 \mu \mathrm{M}$ GHRH (1-29) $\mathrm{NH}_{2}$ or GHRH antagonist JMR-132.

(CtBP1) in LNCaP prostate cancer cell line in vitro. $\mathrm{LNCaP}$ prostate cancer cell line cultured in vitro was exposed to $1 \mu \mathrm{M}$ GHRH antagonist JMR-132 and GHRH (1-29) $\mathrm{NH}_{2}$. The expression levels of the CtBP1 were detected by Western blot. The CtBP1 protein expression was downregulated in the cells cultured with GHRH antagonist JMR-132 (RI: 0.381), while the exposure to GHRH (1-29) $\mathrm{NH}_{2}$ upregulated its expression (RI: 0.987) as compared to controls (RI: 0.049). The results are shown in Fig. 6.

\section{Discussion}

GHRH and its receptor have been shown to play a crucial role in the proliferation of a variety of established cell lines. In this study, we investigated by Western blots the expression of GHRH and GHRH-R in cancerous and non-cancerous cells. Positive and negative controls were used in all our experiments. The expression of GHRH was detected in the UMC11 lung cancer cell line, WPMY-1 human prostate stromal cell line, 3T3 mouse fibroblast cell line and benign prostate cell line BPH-1. These results further extend previous findings on the autocrine and paracrine action of GHRH in cancer cells. The GHRH-R receptor was expressed in SKOV3 ovarian cancer cell line and A549 lung cancer cell line.
We exposed LNCaP prostate cancer cells to the GHRH agonist JI-38 and detected the expression of the major proliferative marker PCNA. These cells were previously shown to respond to GHRH (1-29) $\mathrm{NH}_{2}$, by increasing their proliferation rate as well as the expression of PCNA (11). Our results show for the first time that JI-38 can strongly increase the expression of this proliferation marker.

NSCLC A549 cells, which express GHRH-R, were incubated with GHRH, GHRH agonist JI-38 and GHRH antagonist MZ-5-156. GHRH and JI-38 increased and MZ-5-156 decreased proliferative markers such as cyclin D3 and PCNA. Cyclin D3, a D-type cyclin, plays a prominent role in differentiation and proliferation (24) and is highly expressed in various cancers $(25,26)$. Furthermore, this cyclin is considered a major therapeutic target for cancer (26). GHRH antagonist strongly suppressed the expression of this cyclin, shedding light on the mechanisms of action of these compounds. In contrast, GHRH and JI-38 upregulated the expression of this protein which contributes to their mitogenic effects. Proliferative cell nuclear antigen, a factor of DNA polymerases that encircles DNA and orchestrates genome duplication and reproduction (16), was also downregulated by MZ-5-156 and upregulated by GHRH. These molecular events underline the strong influence of these peptide analogs in cancers.

We also exposed the prostate cancer cell line LNCaP which expresses GHRH-R $(11)$ and wt-p53 $(27,28)$ to GHRH agonist JI-38 in order to study the effect of this compound on the p53 tumor suppressor protein. JI-38 strongly suppressed the expression of $\mathrm{p} 53$, in accord with previous results which reported downregulation of this protein by GHRH (11). Tumor suppressor protein $\mathrm{p} 53$, which suppresses the promoter of PCNA (29), plays a crucial role in cancer, since the loss of its functionality occurs during the development of most tumor types (30). PCNA also plays a critical role in regulating the stability of p53, since its inactivation of PCNA can induce the stabilization of p53 (31). In addition, we examined the expression of the C-terminal-binding protein 1 (CtBP1), which is involved in the promotion of tumorigenesis under hypoxic stress by sensing cellular redox changes (21) and which is activated by a decrease in $\mathrm{NAD}^{+} / \mathrm{NADH}$ ratio (32). The expression of CtBP1 was downregulated after exposure to GHRH antagonist and upregulated after culturing with GHRH.

Collectively, our data support previous findings on the role of GHRH in carcinogenesis and underline the importance of GHRH antagonists as prospective anticancer agents. The applications of GHRH antagonists in diseases related to oxidative stress cannot be excluded, since the dysregulation of the metabolism of reactive oxygen and nitrogen species is involved in a variety of conditions related to increased oxidative stress (33).

\section{Acknowledgements}

The work described in this paper was supported by the Medical Research Service of the Veterans Affairs Department, University of Miami Miller School of Medicine, Departments of Pathology and Medicine, Division of Hematology/ Oncology, the South Florida Veterans Affairs Foundation for Research and Education (AVS). 


\section{References}

1. Thorner MO: The discovery of growth hormone-releasing hormone. J Clin Endocrinol Metab 84: 4671-4676, 1999.

2. Kiaris H, Schally AV and Kalofoutis A: Extrapituitary effects of the growth hormone-releasing hormone. Vitam Horm 70: 1-24, 2005.

3. Mayo KE, Miller T, DeAlmeida V, Godfrey P, Zheng J and Cunha SR: Regulation of the pituitary somatotroph cell by GHRH and its receptor. Recent Prog Horm Res 55: 237-266, 2000.

4. Schally AV: New approaches to the therapy of various tumors based on peptide analogues. Horm Metab Res 40: 315-322, 2008

5. Barabutis N, Tsellou E, Schally AV, Kouloheri S, Kalofoutis A and Kiaris H: Stimulation of proliferation of MCF-7 breast cancer cells by a transfected splice variant of growth hormonereleasing hormone receptor. Proc Natl Acad Sci USA 104: 5575-5579, 2007.

6. Barabutis N, Siejka A, Schally AV, Block NL, Cai R and Varga JL: Activation of mitogen-activated protein kinases by a splice variant of GHRH receptor. J Mol Endocrinol 44: 127-134, 2010

7. Siejka A, Schally AV and Barabutis N: Activation of Janus kinase/signal transductor and activator of transcription 3 pathway by growth hormone-releasing hormone. Cell Mol Life Sci (In press).

8. Kiaris H, Chatzistamou I, Schally AV, Halmos G, Varga JL, Koutselini $\mathrm{H}$ and Kalofoutis A: Ligand-dependent and independent effects of splice variant 1 of growth hormonereleasing hormone receptor. Proc Natl Acad Sci USA 100 9512-9517, 2003.

9. Barabutis $\mathrm{N}$ and Schally AV: Knocking down gene expression for growth hormone-releasing hormone inhibits proliferation of human cancer cell lines. Br J Cancer 98: 1790-1796, 2008.

10. Kiaris H, Schally AV, Varga JL, Groot K and Armatis P: Growth hormone-releasing hormone: an autocrine growth factor for small cell lung carcinoma. Proc Natl Acad Sci USA 96: 14894-14898, 1999

11. Barabutis $\mathrm{N}$ and Schally AV: Antioxidant activity of growth hormone-releasing hormone antagonists in LNCaP human prostate cancer line. Proc Natl Acad Sci USA 105: 20470-20475, 2008

12. Engel JB and Schally AV: Drug Insight: clinical use of agonists and antagonists of luteinizing-hormone-releasing hormone. Nat Clin Pract Endocrinol Metab 3: 157-167, 2007.

13. Izdebski J, Pinski J, Horvath JE, Halmos G, Groot K and Schally AV: Synthesis and biological evaluation of superactive agonists of growth hormone-releasing hormone. Proc Natl Acad Sci USA 92: 4872-4876, 1995.

14. Kiaris H, Koutsilieris M, Kalofoutis A and Schally AV: Growth hormone-releasing hormone and extra-pituitary tumorigenesis: therapeutic and diagnostic applications of growth hormonereleasing hormone antagonists. Expert Opin Investig Drugs 12 . 1385-1394, 2003.

15. Zarandi M, Kovacs M, Horvath JE, Toth K, Halmos G, Groot K, Nagy A, Kele Z and Schally AV: Synthesis and in vitro evaluation of new potent antagonists of growth hormone-releasing hormone (GH-RH). Peptides 18: 423-430, 1997.

16. Moldovan GL, Pfander B and Jentsch S: PCNA, the maestro of the replication fork. Cell 129: 665-679, 2007.
17. Satyanarayana A and Kaldis P: Mammalian cell-cycle regulation: several $\mathrm{Cdks}$, numerous cyclins and diverse compensatory mechanisms. Oncogene 28: 2925-2939, 2009.

18. Lane DP: Cancer. p53, guardian of the genome. Nature 358: 15-16, 1992.

19. Paliwal S, Pande S, Kovi RC, Sharpless NE, Bardeesy N and Grossman SR: Targeting of $\mathrm{C}$-terminal binding protein $(\mathrm{CtBP})$ by ARF results in p53-independent apoptosis. Mol Cell Biol 26: 2360-2372, 2006

20. Wang SY, Iordanov M and Zhang Q: c-Jun NH2-terminal kinase promotes apoptosis by down-regulating the transcriptional co-repressor CtBP. J Biol Chem 281: 34810-34815, 2006.

21. Zhang Q, Wang SY, Nottke AC, Rocheleau JV, Piston DW and Goodman RH: Redox sensor CtBP mediates hypoxia-induced tumor cell migration. Proc Natl Acad Sci USA 103: 9029-9033, 2006.

22. Hayward SW, Dahiya R, Cunha GR, Bartek J, Deshpande N and Narayan P: Establishment and characterization of an immortalized but non-transformed human prostate epithelial cell line: BPH-1. In Vitro Cell Dev Biol Anim 31: 14-24, 1995.

23. Zeitler P and Siriwardana G: Stimulation of mitogen-activated protein kinase pathway in rat somatotrophs by growth hormonereleasing hormone. Endocrine 12: 257-264, 2000.

24. Bartkova J, Lukas J, Strauss M and Bartek J: Cyclin D3: requirement for $\mathrm{G} 1 / \mathrm{S}$ transition and high abundance in quiescent tissues suggest a dual role in proliferation and differentiation. Oncogene 17: 1027-1037, 1998.

25. Carnero A: Targeting the cell cycle for cancer therapy. Br J Cancer 87: 129-133, 2002.

26. Lapenna $\mathrm{S}$ and Giordano A: Cell cycle kinases as therapeutic targets for cancer. Nat Rev Drug Discov 8: 547-566, 2009.

27. Gurova KV, Roklin OW, Krivokrysenko VI, Chumakov PM, Cohen MB, Feinstein E and Gudkov AV: Expression of prostate specific antigen (PSA) is negatively regulated by p53. Oncogene 21: $153-157,2002$.

28. Zhang Z, Li M, Wang H, Agrawal S and Zhang R: Antisense therapy targeting MDM2 oncogene in prostate cancer: Effects on proliferation, apoptosis, multiple gene expression, and chemotherapy. Proc Natl Acad Sci USA 100: 11636-11641, 2003.

29. Morris GF, Bischoff JR and Mathews MB: Transcriptional activation of the human proliferating-cell nuclear antigen promoter by p53. Proc Natl Acad Sci USA 93: 895-899, 1996.

30. Meek DW: Tumour suppression by p53: a role for the DNA damage response? Nat Rev Cancer 9: 714-723, 2009.

31. Banks D, Wu M, Higa LA, Gavrilova N, Quan J, Ye T, Kobayashi R, Sun $\mathrm{H}$ and Zhang H: L2DTL/CDT2 and PCNA interact with p53 and regulate p53 polyubiquitination and protein stability through MDM2 and CUL4A/DDB1 complexes. Cell Cycle 5: 1719-1729, 2006.

32. Yang J, Kong $X$ and Hanson RW: C-Terminal Binding Protein 1 (CTBP1) and the redox control the PEPCK-C gene transcription. FASEB J 22: 782-785, 2008.

33. Janssen-Heininger YM, Mossman BT, Heintz NH, Forman HJ, Kalyanaraman B, Finkel T, Stamler JS, Rhee SG and van der Vliet A: Redox-based regulation of signal transduction: principles, pitfalls, and promises. Free Radic Biol Med 45: 1-17, 2008. 